REVISTA DE DERECHO UNED, NÚM. 8, 2011

\title{
LA REVISIÓN DEL MODELO DE GESTIÓN PÚBLICA: EFECTOS DE LA REPOSICIÓN DEL ÁMBITO PRIVADO EN EL MARCO JURÍDICO PÚBLICO
}

THE REVIEW OF PUBLIC MANAGEMENT MODEL: EFFECTS OF REINSTATEMENT OF THE FIELD PRIVATE IN THE PUBLIC LAW FRAMEWORK

\author{
JULIÁN TORRADO SANCHO \\ Licenciado en $\mathrm{H}^{\mathrm{a}}$ Moderna y Contemporánea. UAM \\ Máster de Ingeniería de Software. UPM \\ DEA. Doctorando en Derecho. UNED
}

Resumen: Los procesos de transformación en la Gestión Pública han actuado en las funciones y organización de la Administración, produciendo cambios que han afectado tanto a las relaciones entre el ámbito público y privado, en el seno de los poderes públicos y sus órganos administrativos, como entre los procedimientos técnicos y jurídicos que los conforman. Una revisión de estos fenómenos lleva a la necesidad de realizar un estudio más profundo y objetivo acerca del papel del marco jurídico público y, especialmente, el régimen jurídico administrativo, ante la necesidad de abrir nuevos enfoques y perspectivas sobre la situación del Estado de Derecho.

Palabras clave: Administración pública, derecho administrativo, derecho constitucional, nueva gestión pública, derecho privado, reforma administrativa, gobernanza, intervención pública, estado social, privatización.

Abstract: The transformation processes in public management have acted on the functions and organization of the administration, producing changes that have affected both the relationships between 
the public and private, within public authorities and administrative bodies, and between technical and legal procedures that conform. A review of these phenomena leads to the need for a more thorough and objective study on the role of public legal framework, especially the administrative legal system, given the need to open up new approaches and perspectives on the status of the rule of law.

Key words: Public administration, administrative law, constitutional law, new public management, private law, administrative reform, governance, public intervention, welfare state, privatization.

Sumario: I.- La fuente constitucional en la organización política de la acción pública. I.1.-La conexión entre los poderes públicos, el Gobierno y la acción de la Administración en el ámbito constitucional. I.2.-Principios básicos de la vinculación del ordenamiento jurídicoadministrativo al Constitucional. II.-Reposición del ámbito privado: la gestión pública sujeto de políticas y la actividad administrativa objeto de instrumentos técnicos de organización y control. III.-La corrección de los modelos privatistas de gestión y la búsqueda de entornos de cooperación entre el ámbito público y privado. IV.-La marginalidad del marco jurídico en la nueva gestión de los servicios públicos y sus formas de superación.

\section{LA FUENTE CONSTITUCIONAL EN LA ORGANIZACIÓN POLÍTICA DE LA ACCIÓN PÚBLICA}

\section{I.1. La conexión entre los poderes públicos, el Gobierno y la acción de la Administración en el ámbito constitucional}

La gran diversidad de aspectos que presenta la Administración no impide, sino más bien aconseja, a efectos de facilitar su comprensión, considerar la unidad entre los principios jurídicos, la organización y el funcionamiento de la Administración, que se sustancia en la actividad del Estado a través del marco jurídico y técnico con el que éste opera en cada uno de sus poderes. Por otro lado, la necesaria estabilidad y cohesión social para el cumplimiento de los fines que tiene encomendados el Estado impone articular su legitimación a partir de una definición política de los poderes públicos, que permita tutelar el interés general por medio de procedimientos que garanticen este propósito a través de la participación y sanción de la sociedad a la que dicho Estado sirve. Puede deducirse, en este sentido, que la conexión entre los poderes públicos y la acción de la Administración procede de la legitimación previa que éstos obtienen consagrando el 
principio democrático en la legalidad a través de la norma constitucional, y que sin las garantías que ésta establece no cabe funcionamiento eficaz de los poderes públicos.

Por lo tanto, en la creación del Estado liberal prevalece un sentido histórico de continuidad, pues a la existencia de un Estado dado, sea liberal o absolutista del Antiguo Régimen, le precede una sociedad ya conformada con caracteres de autorregulación privada, relaciones comunitarias y convenciones públicas establecidas, y asimismo un sentido correctivo e innovador que trata de satisfacer, en la conjugación de intereses en presencia, la superación de problemas de organización y funcionamiento que afectan a la generalidad de la sociedad $^{1}$. Es por ello que el marco político, que precede a la organización del Estado liberal y toda su actuación pública, precisa una formulación desde el propio marco jurídico, pues sólo éste puede expresar los principios y normas, que definen el ideal de organización social al que sirven los poderes públicos, al aplicar una técnica específica que establece, con el suficiente rigor y adecuada continuidad con el pasado, los elementos constitutivos del Estado ${ }^{2}$. Esta realidad tangible en la experiencia histórica, que lleva al Estado liberal-democrático a su conformación y evolución, se debe acompañar, como siguiente cláusula, de su definición desde el plano jurídico, es decir, desde el conjunto de normas que se forman en el Derecho, por lo tanto, motivadas en el reconocimiento y aceptación por la sociedad política de ser las más fundadas en principios de equilibrio y equidad

${ }^{1}$ Un ejemplo, citado por Tocqueville, lo supone el régimen foral vascongado, cuya continuidad como sistema institucional procede de su carácter innovador para la sociedad vasca dentro de las posibilidades jurídicas del Antiguo Régimen. Su confrontación con el régimen liberal viene dada en gran medida por la vigencia de su marco político y jurídico en el seno del nuevo sistema socio-económico al que se había anticipado y adaptado gestando instrumentos modernos de soberanía dentro la Monarquía de España: «En España ciertas provincias tenían la facultad de establecer un sistema de aduanas propio, facultad que tiende por su esencia misma a la soberanía nacional (...) Verdad es que en Francia y en España estando siempre el poder real en disposición de ejecutar por la fuerza, en caso de necesidad, lo que la constitución del reino le rehusaba hacer de derecho, se llegaría en suma al mismo punto al que me refiero [centralización]» (Tocoueville, Alexis de. La Democracia en América. Madrid, J. Trujillo, 1854. pág. 83).

${ }^{2}$ Desde la perspectiva del Derecho positivo se asumen dos premisas kelnesianas: por una parte esta investigación se basa en el Derecho positivo liberal democrático que parte de la formulación de un ideal específico, sin el cual no puede darse ninguna aplicación jurídica. En resumen no hay norma positiva sin ideal específico aplicado al Derecho, cuyo concepto sin embargo, desprendido de juicio de valor, encierra la técnica social que eleva al marco jurídico al medio adecuado de organización del Estado. Vid. Kelsen, Hans. Teoría General del Derecho y del Estado. Mexico, UNAM, 1958. $2^{\mathrm{a}}$ Ed. págs. 4-6. 
conducentes a los fines que se ha dado, y por otro lado eficaces en su puesta en práctica ${ }^{3}$.

A partir de estas premisas el Estado emerge como el marco cada vez más presente en la vida de las sociedades avanzadas, sea en el ámbito público como privado, en el plano colectivo como individual, y lo hace, una vez constituido, a través de las acciones de la Administración que se extiende a los diferentes órganos políticos además de las actividades de dirección y gestión de que se sirven ${ }^{4}$. Sin embargo, entre el Estado y su actividad ejecutora existe una organización política que debe dirigir la acción pública, y como tal sólo una norma jurídica suprema puede ejercer de medio regulador en conexión directa con la delegación de la soberanía política. Sin esta organización y delegación desde los poderes del Estado en su forma jurídica constitucional, sólo cabe el mero uso instrumental de sus herramientas últimas de actuación, con la pérdida de la legitimidad política, lo que se puede producir fuera del Estado liberal-democrático o ensayando regímenes de poder que en términos históricos se puede considerar que no tienen posibilidades de estabilidad y permanencia.

Por todo ello, el marco jurídico penetra en la organización del Estado desde el propio ordenamiento constitucional, por un lado estableciendo la estructura orgánica y competencial para el desempeño de sus fines con superioridad jerárquica y funcional sobre el resto de los criterios y técnicas de la ejecución política y administrativa. Además, dicho marco asume un orden jurisdiccional previo en la forma de realizarse las actuaciones tanto de dirección política como especialmente administrativas, esa forma corresponde al Estado de Derecho, pues garantiza el cumplimiento de la legalidad a través de

3 «La Constitución, producto del constituyente, surge así de la propia sociedad para organizar los poderes del Estado. La Constitución es, por tanto, una norma que de forma sistemática trata de organizar la vida de la comunidad, regulando, al menos, dos grandes cuestiones: las relaciones entre los individuos y el Estado y las funciones fundamentales del Estado y sus órganos, el ámbito de sus competencias y las relaciones entre éstos». (RAJOY BREY, Mariano. Presentación. En VV.AA. Administraciones Públicas y Constitución. Reflexiones sobre el XX Aniversario de la Constitución Española de 1978. Madrid, MAP, 1998. pág. 19).

${ }^{4}$ González Hernández, citando a Bernard Chenot afirma: «En efecto, cualquier hecho social revela una relación entre dos abstracciones que tienen el mismo objeto: el ser humano. En uno de los dos extremos de la relación está el individuo aislado y en el otro, el conjunto de individuos agrupados en colectividad. En este sentido, la antinomia individuo-Estado cubre la unidad del problema social». Vid. BERNARD CHENOT, Organisation économique de L'Éta., Paris, Dalloz, 1995. pág. 8 y s). (GonZÁLEz HernánDEZ, Juan Carlos. La Constitución y la Ciencia de la Administración. En VV. AA.. Administraciones Públicas y Constitución. Reflexiones sobre el XX Aniversario de la Constitución Española de 1978. Madrid, MAP, 1998. pág. 322). 
mecanismos jurídicos y judiciales. La conexión entre ese orden constitucional y el funcionamiento del Estado de Derecho se sustancia en la incorporación de principios que conectan el Gobierno democrático y el Estado liberal en el funcionamiento de la Administración y la demanda de actualización de los principios del Derecho administrativo en orden a la preeminencia de los mandatos constitucionales tales como el respeto a los Derechos fundamentales, la plena potestad del órgano legislativo en la separación de poderes, el principio de representación democrática en el ejercicio de la soberanía, la superioridad jerárquica de las fuentes normativas del bloque de constitucionalidad y los instrumentos constitucionales de control al Gobierno ${ }^{5}$. Con todo, éste marco jurídico público en su conjunto define y regula la dirección política de la Administración y con ella de los instrumentos ejecutores del Estado, la Constitución le reconoce su facultad y amplias capacidades ejecutorias, que más allá del reconocimiento de la jurisdicción administrativa como forma de control intrínseca de ese poder instrumental otorgado a la Administración, establece la conexión de ésta con el Gobierno constitucional que obliga a nuevas formas de control político, de rendición de cuentas y de supeditación a la legalidad, que en los principios constitucionales supone, a través del avance del bloque de constitucionalidad, una realidad jurídica dinámica $^{6}$.

\section{I.2. Principios básicos de la vinculación del ordenamiento jurídico-administrativo al Constitucional}

La conexión entre el marco jurídico y técnico en la actividad de la gestión pública se debe considerar una cuestión clave como instrumento para los fines del Estado. En efecto, el primer marco se

${ }^{5}$ Es interesante traer a colación como va evolucionando la doctrina política que recoje el Derecho Constitucional, así Álvarez Conde sostiene: «En consecuencia la Constitución [...] ha dado lugar a un Derecho Constitucional fundado más que en el principio de división de poderes, principio que puede resultar obsoleto dado que todos los órganos del Estado tienen atribuidos, con mayor o menor alcance, poderes de naturaleza legislativa, ejecutiva y judicial, en la división de los órganos estatales entre los diversos órganos constitucionales». (ÁLvAFREz CONDE, Enrique y Javier García Fernández. «La Constitución y el Derecho Constitucional» en VV.AA. Administraciones Públicas y Constitución. Reflexiones sobre el XX Aniversario de la Constitución Española de 1978. Madrid, MAP, 1998. pág. 206)

${ }^{6}$ «Para que el Derecho constitucional se configure como una verdadera disciplina jurídica y se distancie de los enfoques politológicos o sociológicos propios del viejo Derecho Público español, necesita fundamentarse en relaciones jurídicas. A su vez, los sujetos de esas relaciones jurídicas deben ser auténticas personas jurídicas que actúan interna y externamente a través de órganos jurídicos» (Ibid. pág. 206). 
sostiene sobre principios de Derecho, pues sin ellos resulta de extremada dificultad establecer la concatenación de enunciados generales y fines concretos que se requieren para trazar las líneas del entramado jurídico positivo ${ }^{7}$. Por otra parte se puede aceptar como realidad en la aplicación de la doctrina jurídica, que el engarce entre Derecho Constitucional y Derecho Administrativo no se ha llevado siempre a efecto y como consecuencia su nexo doctrinal no es pacífico, sino más bien un proceso que parece que avance en dicha dirección aunque no siempre interese profundizar en ella ${ }^{8}$. Asimismo, se entiende que dicha separación podría ser consecuencia de la disociación que se produce en los Estados liberales entre la evolución de las instituciones bajo ciertas pautas de continuidad, y los frecuentes cambios que se han dado en el modelo constitucionalista continental ante la cíclica ruptura de los regímenes políticos que causan estos

\footnotetext{
${ }^{7}$ Más allá de cierta radical posición de abstracción jurídica positivista el gran jurista austriaco, sirviéndose de ésta, establece consideraciones de indudable autoridad y claridad, entre otras, que las leyes deben aplicar principios previamente dictados que se sustancian en la constitución. «La constitución prohíbe que las leyes tengan cierto contenido y ordena que posean tal otro; de modo que la ley es «ejecución» de la constitución, de la misma manera que la sentencia es ejecución de la ley». (KELSEN, Hans. Teoría General del Estado. Editora Nacional. Madrid, 1979, pág.390)

${ }^{8}$ Respecto a la peculiar relación entre Derecho Administrativo y Constitucional (o Político, en referencia a su otro tratamiento histórico) que incluye su relativa suplantación recíproca, es esclarecedor este comentario: «No obstante, el Derecho político no ha cumplido esta función en un país como el nuestro, caracterizado, como ha recordado Rubio Llorente, no sólo por la ruptura, sino por el abandono del orden constitucional. La ausencia de Constitución en nuestro país ha facilitado que históricamente el Derecho administrativo hiciera las veces de Derecho constitucional. Nacieron al calor de esta ciencia jurídica y al vacío del Derecho constitucional un conjunto de conceptos que eran, en el fondo, una garantía de los derechos de los ciudadanos y del funcionamiento del Estado y una adaptación de categorías extranjeras, principalmente francesas. De esta manera, la Administración pública se configuró en nuestro país desde la ciencia administrativa y desde la legislación, y al margen de una norma constitucional principal». (TRONCOSO REIGADA, Antonio. »Dogmática administrativa y Derecho Constitucional: el caso del servicio público». Revista española de Derecho Constitucional. Núm. 57, Septiembre-Diciembre, 1999.pág. 88).

${ }^{9}$ Puede advertirse una contradicción en este punto en el aserto de Díaz Lema sobre la causa de esta divergencia cuando afirma «...La ausencia de un tratamiento del Derecho Administrativo desde sus bases constitucionales es el fruto de la evolución de la sociedad y del Estado español desde el último siglo y medio, caracterizada por una crisis permanente y una notable falta de estabilidad de las instituciones» Tal vez, por el contrario, ha sido la estabilidad de las instituciones administrativas las que han permitido fijar más la continuidad del Derecho Administrativo y su ciencia jurídica sobreponiéndose a la inestabilidad política o constitucional, siendo de aplicación aquí el caso español a la mayoría de los estados liberales continentales. (DíAz LEMA, José Manuel. «La constitución y el Derecho Administrativo» en VV.AA. Administraciones Públicas y Constitución. Reflexiones sobre el XX Aniversario de la Constitución Española de 1978. Madrid, MAP, 1998. pág. 213).
} 
cambios $^{9}$. Sin embargo, la doctrina, posteriormente, en su corriente pluralista que entre otros desarrolla George Vedel, sienta las bases jurídicas sobre principios de vocación dogmática o irrefutable cuando proclama la reunificación del Derecho constitucional y el Derecho administrativo en el Derecho público, e invoca para ello la unidad del Derecho a partir de la inadmisibilidad de la dualidad de regímenes jurídicos o jurisdiccionales en el ordenamiento jurídico del Estado, ante la que el Estado de Derecho exhibe el principio de jerarquía de las fuentes que resuelve los conflictos entre las normas ${ }^{10}$.

En este sentido, la relevancia del caso de España se debe a que la transformación de su régimen político desde una situación preconstitucional dentro de un Estado autoritario a otra nueva liberal-democrática, permite estudiar en un breve lapso temporal los efectos del Estado constitucional en el régimen jurídico administrativo, incluso la influencia entre ambos a través del análisis de las sucesivas reformas que se producen a lo largo del proceso de consolidación del Estado constitucional ${ }^{11}$. La solución de continuidad de un cambio político que preserva las instituciones heredadas y el ordenamiento jurídico administrativo no amparado por una disposición constituyente permite indagar en la relación entre el sistema político constitucional y el régimen jurídico de la Administración como sujetos independientes en la organización del Estado ${ }^{12}$.

${ }^{10}$ Este concepto queda glosado en Vid. Alli Aranguren, Juan-Cruz. Derecho Administrativo y globalización. Navarra, Thomson-Civitas, 2004. Pág. 145. Vid. VEDEL, George. "Cour des comptes et juge administratif» en La Cour des comptes d'hier à demain Paris, 1979.

${ }^{11}$ En el planteamiento de este trabajo comienza con la siguiente formulación: «La Constitución de 1978 deroga expresamente todas y cada una de las Normas fundamentales que habían estado vigentes en el periodo anterior de la Historia de España durante cuarenta años y en la breve transición política ya bajo la Corona. De un modo genérico, pero no impreciso, quedaron también derogadas cuantas disposiciones se opongan a lo establecido en la Constitución, lo que ha permitido numerosos pronunciamientos del Tribunal Constitucional, que también sentó la doctrina de la «continuidad del ordenamiento jurídico» (STC 76/1986, de junio) para evitar vacíos jurídicos en un plausible y práctico objetivo de servir a la seguridad jurídica, que es también un principio constitucional (art. 9.3. CE).» (MEILÁN GIL, José Luis. «La Administración Pública: naturaleza jurídica» en VV. AA.. Administraciones Públicas y Constitución. Reflexiones sobre el XX Aniversario de la Constitución Española de 1978. Madrid, MAP, 1998).

12 «Esta situación dada no llevó necesariamente a un desarrollo negativo de las instituciones jurídicas sino, en ocasiones, ocurrió todo lo contrario. En el pasado más reciente, el ordenamiento administrativo cumplió, de modo ejemplar, una función de limitar los abusos del Estado franquista. El Derecho administrativo suplantó al Derecho Constitucional, tratando de juridificar al máximo el poder y defendiendo al administrado con un conjunto de garantías frente a las inmunidades del poder». (Troncoso Reigada, Antonio. Dogmática... Op. cit., pág. 88) 
Las diferencias del ordenamiento de la CE de 1978 respecto a la legislación de Derecho Administrativo de los años de 1950 y la Ley reguladora de la Jurisdicción Contenciosa-Administrativa, de 27 de diciembre de 1956 (LJCA) permite a Díaz Lema destacar los siguientes aspectos diferenciales entre aquella legislación y el nuevo ordenamiento: el derecho de la tutela judicial que proclama el art. 24 de la CE y la garantía de los derechos fundamentales; la división de poderes y la asunción del principio de legalidad en la Administración como sustrato del Estado de Derecho que se define en la propia Constitución; dentro del bloque constitucional, la Ley Orgánica del Tribunal Constitucional que regula en los arts. 42 y 44 el derecho de amparo como figura que permite el recurso ante cualquier acto de los poderes del Estado -sean órganos judiciales, legislativos o las propias administraciones-, que vulnere los derechos y libertades protegidos por la Constitución, garantía extensible también a los actos con valor de ley a través del recurso extraordinario o cuestión de inconstitucionalidad ante el TC, cuya iniciativa no corresponde a particulares $^{13}$. Por otra parte, al tiempo que la materia legislativa parece que escapa a las garantías sobre el control directo de la constitucionalidad por los particulares, se amplía para ellos a dos conceptos de gran interés:

a) La ampliación como sujetos de garantía jurídica de los actos administrativos al conjunto de resoluciones de cualquier órgano o poder estatal que no correspondan a la Administración, por ejemplo, las resoluciones judiciales o de las cámaras legislativas, sean éstas las Cortes o Parlamentos autonómicos, y el reconocimiento como contenedor de este conjunto a la personalidad jurídica única del Estado o los poderes públicos autonómicos a los cuales también se adscribe la Administración como sistema interrelacionado.

b) La tutela judicial de la responsabilidad de los órganos estatales dentro de esa personalidad jurídica unificada, con independencia de qué ente o poder público actúe, que sustancia las garantías que la Constitución otorga por un lado a la prevalencia de los derechos ciudadanos y por otro a la unificación del fuero de los órganos estatales ante ellos, es decir, vincula indistintamente al Estado con

${ }^{13}$ Vid. Díaz Lema,... Op. Cit. pág. 215-216. Matiza Díaz Lema cómo, no obstante, la legislación que desarrolla también dentro del bloque de constitucionalidad el resto del poder judicial (LOPJ) amplía tanto la extensión de los actos administrativos a los producidos por otros órganos del Estado, como con ellos la vía de recursos por la jurisdicción ordinaria, y de forma especial la jurisdicción contenciosa-administrativa. 
sus órganos por el estatuto que la Constitución superpone a sus regímenes jurídicos particulares.

En el caso de la CE los efectos del ordenamiento constitucional sobre el régimen administrativo anterior se aprecian en primer término en tutelas judiciales como el control de la actividad discrecional técnica que revertirá en contradicciones entre tales garantías jurídicas añadidas y los principios de eficacia y eficiencia que introducen las nuevas técnicas de gestión pública. Más inconclusa en su desarrollo jurisprudencial y doctrinal, como se ha visto con anterioridad, es la tutela judicial de los actos gubernamentales, que si bien aparece como fórmula garantizadora opuesta a la inmunidad del pasado gobierno autoritario, queda matizada por la doctrina que diferencia los actos de dirección política de los actos administrativos, con el fin de salvaguardar la división de poderes y evitar una libre intromisión del poder judicial en el poder ejecutivo, estas resoluciones se adoptan en cada caso, destacando entre ellas la sentencia del Tribunal de Conflictos de Jurisdicción de 14 de diciembre de 1995 sobre el acceso por los juzgados a materias de secretos oficiales. Ante la acción administrativa estas garantías constitucionales de derechos y libertades se completan con las medidas cautelares por los actos administrativos que exigen la ejecución forzosa, como la entrada en domicilios. Una vez más queda abierto el conflicto entre los principios de privilegio ejecutorio, heredados de la doctrina administrativista clásica ${ }^{14}$ y la necesidad de la garantía de los derechos, cuyo trasfondo procede de la dispar obligación por el Estado liberal de proteger los intereses generales y tutelar los derechos y libertades individuales ${ }^{15}$.

Pero a esta contradicción típica debe ser ajeno el ordenamiento constitucional, que si algo enuncia con claridad es la jerarquía de los derechos y libertades sobre los demás medios establecidos por el Estado para asegurar su cumplimiento. De algún modo el interés ge-

${ }^{14}$ Se considera en general, dentro de esta investigación, doctrina administrativa clásica a la desarrollada dentro del primer constitucionalismo liberal, en el caso de España se aplicaría a la surgida anteriormente a la Constitución vigente. Se exceptúa en muchos aspectos a las corrientes introducidas en los años 50, que aún siendo preconstitucionales inspiran en gran medida la doctrina jurídico administrativa de la actual CE basadas ambas en las corrientes administrativas europeas contemporáneas, situándose en diversas áreas de establecimiento de garantías en su vanguardia.

${ }^{15}$ Vid. DíAz LEMA, ... Op. Cit. La síntesis que presenta se analiza subrayando los efectos en el Derecho Administrativo de la CE en su vertiente de tutela y garantías de los derechos y libertades individuales, enfoque preeminente en un Estado cuya constitucionalidad surge de las tinieblas políticas del autoritarismo y la vulneración de los pilares del liberalismo político y el Estado democrático. 
neral como principio en el que se basa en gran medida el ordenamiento jurídico administrativo para fijar su posición subjetiva respecto a los ciudadanos en su calidad de administrados, puede entenderse como un medio para que el conjunto de derechos individuales se encuentren amparados, aun cuando no tengan presencia singular y concreta en un acto administrativo dado, y por ello, no como motivación para impedir o dificultar la legítima aspiración particular de un ciudadano, por el contrario, personado en el acto, al ejercicio de un derecho, o por extensión en el Estado prestacional, el acceso a un servicio público sobre el que posee sustancialmente un derecho reconocido.

De principal aplicación también resultan el conjunto de principios recogidos en el capítulo III del Título I CE que se viene citando. El enfoque que se pretende en este estudio no radica en su materia social y económica, sino en su naturaleza jurídica, pues si la garantía de los Derechos y Libertades corresponde en diferentes grados al conjunto de los poderes públicos, éstos principios, que se aplican a todos ellos, lo hacen de forma implícita y en primer término al Gobierno como proponente y ejecutor de la legislación positiva, y a la Administración Pública como poder público implicado en las actuaciones que a través de la práctica administrativa debe tutelarlos en virtud del art. 53.3 CE. Es difícil de eludir en la generalidad del término poderes públicos la responsabilidad de la función ejecutiva del Gobierno y la Administración en el cumplimiento de los derechos y deberes fundamentales y los principios rectores de la política social y económica del Título I, bien sea en su vinculación negativa, como sugiere parte de la doctrina, en el sentido de no poder ir en contra de ellos, o por la vía del art. 9.2 CE, que se entiende aquí como un mandato positivo y diáfano ${ }^{16}$ :

Corresponde a los poderes públicos promover las condiciones para que la libertad y la igualdad del individuo y de los grupos en que se integra sean reales y efectivas; remover los obstáculos que impidan o dificulten su plenitud y facilitar la participación de todos los ciudadanos en la vida política, económica, cultural y social.

Expresamente de lo entresacado, y sin ningún ánimo de forzamiento en la interpretación de la norma constitucional, se deduce un imperativo jurídico positivo tanto en el desarrollo normativo y su interpretación, como en la práctica de aplicación administrativa, sin que la reserva de Ley del citado art. 53.3 CE permita anular la tutela jurisdiccional de tan concreto artículo y sin perjuicio de lo que se pueda desprender de ese mandato para la invocación directa en la ju-

${ }^{16}$ MeILÁn GIL, José Luis... Op. Cit. pág. 499. 
risdicción ordinaria de los principios rectores del capítulo III de la $\mathrm{CE}^{17}$.

\section{REPOSICIÓN DEL ÁMBITO PRIVADO: LA GESTIÓN PÚBLICA SUJETO DE POLÍTICAS Y LA ACTIVIDAD ADMINISTRATIVA OBJETO DE INSTRUMENTOS TÉCNICOS DE ORGANIZACIÓN Y CONTROL}

El marco jurídico propio de la Administración, de acuerdo con lo visto en el epígrafe anterior, no sólo se encuentra constreñido por el ordenamiento constitucional, sino que dentro de ella actúa un marco técnico que acentúa su delimitación en la evolución del Estado liberal-democrático hasta, tal vez, las drásticas consecuencias de la reforma de la Administración surgida en la crisis del Estado del Bienestar. Afectación que, como ya se ha venido mostrando por el estudio de las prácticas en la Administración, incide en el conjunto del Derecho público.

El gradual paso hacia un nuevo paradigma de la gestión pública se puede definir como un conjunto homogéneo de líneas de actuación que se acuñan en la tradición anglosajona bajo el término de Nueva Gestión Pública (NGP), y según lo ya introducido encontraría su precedente en el impulso privatizador de principios del siglo XX y a lo largo del desarrollo del welfare state o estado del bienestar en su vertiente crítica $^{18}$. A diferencia de ambos episodios precedentes, la crisis de mediados de los años 70 provoca una inflación y estancamiento económico que el creciente déficit público y los instrumentos administrativos del Estado que sustentan el círculo crecimiento-gasto público no pueden detener sin salirse de él ${ }^{19}$. Esta situación produce un

${ }^{17}$ La STC 19/1982, de 5 de mayo sostiene que el artículo 53.3 de la CE «impide considerar tales principios como normas sin contenido y que obliga a tenerlos presentes en la interpretación tanto de las restantes normas constitucionales como de las leyes» (Ibid. pág. 499).

${ }^{18}$ En su análisis de las premisas del Management Woodrow Wilson, considerado iniciador de la ciencia de la administración en los principios del siglo XX, establece una clara analogía entre aquellas y sus supuestos: «En efecto, en su El estudio de la Administración Pública, Wilson estableció cuatro premisas mayores: 1) la gobernación consiste en dos procesos separados: la política y la administración; 2) la administración puede y debe constituir el objeto de una ciencia diferente de la política; 3) el estudio científico de la Administración Pública conduce al descubrimiento de principios nomotéticos análogos al de las leyes en las ciencias físicas; 4) la aplicación de tales principios asegurará una mayor economía y eficiencia.»(Prats Catalá, Joan. De la burocracia al management, del management a la gobernanza. Las transformaciones de las administraciones públicas de nuestro tiempo. En varios, Estudios para la Reforma de la Administración Pública. Madrid, INAP, 2000. pág. 110). 
cambio en el objeto de las políticas públicas que conlleva una importante e innovadora particularidad. Si hasta entonces el objeto de estas políticas era externo y utilizaba para ello los instrumentos políticos regulatorios de la actividad económica y social por medio de los ordenamientos normativos que fijan las políticas presupuestarias y fiscales de gastos e ingresos, ahora se debe orientar a un objeto interno: la modificación de la organización y la gestión pública, es decir, la transformación de la Administración.

En la óptica aquí abordada, dichas líneas tratan de sustanciar un planteamiento de reforma que resuelva los problemas de funcionamiento del Estado bajo una perspectiva, que si bien aporta la novedad interna mencionada, afecta a la alteración de las relaciones externas de la Administración pública ${ }^{20}$.

Los aspectos internos de la Administración corresponden a las medidas de gestión pública entre las que destacan: la profundización en la crítica a la burocracia como forma de organización predominante; la introducción de nuevos métodos de gestión económica que transformen las técnicas vigentes de gestión presupuestaria de los servicios públicos; la descentralización administrativa y su desagregación en unidades susceptibles de un control gerencial que imite el modelo privado de gestión vinculado a la eficiencia en la producción de los servicios; el control y la evaluación de resultados de la gestión de los servicios públicos. Como corolario y elemento diferencial de cualquier intento precedente de reforma de la Administración liberal, quizá se deba destacar la peculiaridad de la subordinación de estas medidas a las políticas públicas: la propia Administración, tal vez en su crecimiento y complejidad desmedida, se convierte en objeto de los programas políticos y en prioridad de la acción de gobierno, que pasa a ser actor principal de la gestión pública frente a los métodos vigentes esencialmente administrativos de la maquinaria burocrática.

19 «Concretamente, a principios de 1977 los rasgos negativos de la situación económica eran demostrativos de estar en una auténtica depresión: estancamiento en la actividad general, paro creciente y fuertes niveles de inflación y endeudamiento exterior» En España había margen para no incurrir en el paquete de reformas administrativas, pues bastaba con acometer la reforma fiscal, la devaluación de la moneda, y las reformas de saneamiento del modelo económico obsoleto de «crecimiento oligárquico» (Tamames, Ramón . La República ... Op. Cit. pags. 296-298).

${ }^{20}$ La mayoría de los aspectos citados a continuación se mencionan en la obra citada asociándose cada medida a los diferentes diagnósticos políticos de las causas de los fenómenos, otro aspecto importante que se menciona es su común aplicación a todos los países desarrollados. Vid. VILloria MENDIETA, Manuel. La modernización de la Administración como instrumento al servicio de la democracia. Madrid, MAP, 1996. pág. 17-18 
En el ámbito externo intervienen las políticas que determinan la modificación del papel del ámbito privado en su relación con el ámbito público a partir de, entre otras, las siguientes premisas de carácter político-económico: la doctrina de la no injerencia de la Administración en aquellos servicios públicos susceptibles de prestación por el ámbito privado ${ }^{21}$; la doctrina de la restitución del déficit público mediante la reasignación al sector privado de los recursos dedicados al gasto público con la disminución de la presión fiscal y de la intervención pública en la economía; la desregulación de las actividades económicas, epítome del liberalismo económico; por último, la privatización de las empresas y los grandes recursos públicos asignados a la infraestructura y la actividad económica productiva.

Se trata de un proceso de desinstitucionalización y opuesto a la tendencia del Estado burocrático, que genéricamente considerado supone la intervención de un agente dentro del ámbito público que representa los intereses del ámbito privado y actúa en los puestos del gobierno y la Administración designados en el nivel político ${ }^{22}$. A este proceso le acompañan políticas de intervención en lo público que desplazan funciones típicas de éste al ámbito privado y se conectan con medidas e instrumentos de control técnico y reorganización de la gestión pública. A su vez, estos instrumentos modifican los métodos administrativos basados en un marco jurídico homogéneo y propio que garantiza la sujeción no arbitraria de las potestades de la Administración, y en su lugar se acude a esquemas normativos heterogéneos y especiales, y técnicas de gestión exentas de un control jurídico público ${ }^{23}$.

La primera sistematización de estos nuevos principios amalgaman una nueva doctrina de la función del Estado y de los métodos que deben subordinar su acción no a las necesidades de la sociedad objetivamente consideradas, sino a la expresión subjetiva de su voluntad política ejecutada a través de técnicas de gestión que apliquen ésta

${ }^{21}$ «Los procesos de liberalización y privatización aún siendo conceptualmente distintos abedecen a una misma filosofía: determinadas actividades de naturaleza económica en cuya prestación subyace un interés general es mejor que sean prestadas por el sector privado por ser éste más eficiente, reservándose la Administración ciertos mecanismos de control». (Lesmes SERRANO, Carlos. "La externalización de los servicios públicos» en Ortega Martín, Eduardo (Dtor.). Derecho Administrativo del siglo XXI. Madrid, Consejo General del Poder Judicial, Cuadernos de Derecho Judicial, 12, 2007).

${ }^{22}$ Acerca del concepto de institucionalización entendido como proceso histórico véase LIPPI, Andrea y Massimo Morisi. Gestión y Administración públicas. Valencia, Tirant lo Blanch, 2008. Cap. 3

${ }^{23}$ Vid. Villoria MendieTA, Manuel. La modernización ... Op. Cit. págs. 81-84. 
con la mayor eficacia y eficiencia prácticas, obviando las formas jurídicas como principio rector de las actuaciones públicas. Así, ya en 1978 Shelma Muskin define en el estudio «Current Status of Public Management Research» los siguientes elementos centrales de la gestión pública: Políticas de Gestión (Policy management), en la identificación del análisis de necesidades, opciones, programas y asignación de recursos; Gestión de Recursos (Resource Management), que establece una función básica de soporte a través de funciones administrativas, presupuestarias, financieras, de aprovisionamiento y gestión del personal; Gestión de programas (Program Management), con la implementación de las políticas por medio de operaciones y agencias que producen los resultados a través de líneas funcionales de actuación ${ }^{24}$. La principal aportación de este enfoque es considerar la organización pública de la Administración de un modo decididamente convergente con las estructuras privadas o empresariales, donde las organizaciones se comportan como sistemas relacionales con el entorno exterior y con diferentes niveles interdependientes en su estructura interna: un sustrato de toma de decisión que define y ordena las objetivos, otra capa de soporte que brinda los medios de gestión necesarios para el funcionamiento general, y por último, un nivel operativo en el que se producen los bienes y servicios para los que tal organización subsiste de acuerdo con los objetivos definidos.

El origen angloamericano de la nueva gestión pública se convierte en impulsor de las reformas administrativas ${ }^{25}$. Como tal es fuente de los principios generales que el proceso de transformaciones de la acción pública infunde en la generalidad de los Estados liberal-democráticos, si bien no de forma homogénea, consideración que se debe tener presente en las diferentes formas de asimilación de la nueva doctrina pública, tal y como señala Joan Prats:

La Nueva Gestión Pública ha sido el paradigma de reforma administrativa prevaleciente hasta mediados de los noventa, acompañando a la hegemonía de la agenda neoliberal antes descrita. Naturalmente, no se aplicó en todos los países por igual: tuvo gran influencia en los países angloamericanos - aunque con grandes diferencias entre ellos-, menos en los países nórdicos y escasa en los países de matriz latina y germánica. En España, su influencia práctica ha sido escasa aunque desigual. La nueva gerencia pública ha impregnado, desde

\footnotetext{
${ }^{24}$ Recogido por Allinson, Graham, T. «Public and private management; Are they fundamentally Alike in All Unimportant Respects» en Tillman, Richard J. Public Administration. Concepts and Cases. University of Colorado, 1996. $6^{\mathrm{a}} \mathrm{ed}$.

${ }^{25}$ Vid. Barzelay, Michael. La nueva gestión pública. Un acercamiento a la investigación y debate. México, FCE, 2003, pág. 10-17.
} 
luego, el discurso sobre la Administración Pública y legitimado la fuerza que los gerentes han tomado en muchas Administraciones, especialmente locales y autonómicas ${ }^{26}$.

El desarrollo del paradigma de una nueva gestión pública asume dos premisas generales: la posibilidad de medir el desempeño en todos los niveles desde el Gobierno hasta la Administración, y consecuente con ésta, la capacidad de fijar los objetivos entre ambos por medio del conocimiento que esta medición brinda. Con ello se establece la vía contractual como herramienta de garantía de control de los intereses, sean públicos o privados, del ejecutor de los servicios ${ }^{27}$.

En su aplicación al sistema continental, en el que pasamos a centrarnos, subyace una simplificación del uso del marco jurídico en la intervención de los controles y normas que regulan la actividad administrativa, incluyendo las prerrogativas y poderes exorbitantes del régimen jurídico propio. Este hecho por un lado limita su desarrollo y por otro matiza las medidas que se asimilan a la introducción de las nuevas técnicas que adquieren un componente más administrativo y organizativo y adoptan con éxito el término de modernización administrativa ${ }^{28}$.

Tomando el caso de Alemania se observa que las reformas no se separan de las directrices constitucionales de 1949, algunas de ellas sin completar ${ }^{29}$. En ésta ya aparecen marcadas las líneas de descentralización política y desconcentración administrativa en la que los niveles de organización territorial combinan ambas formas. En el ámbito privado la intervención pública, dentro de una economía de mercado, permite la cooperación y colaboración de los sectores implicados: empresarios, empleados y poderes públicos. La fuerte presencia del marco jurídico unido a la burocratización favorecida por

${ }^{26}$ Prats Catalá, Joan. De la burocracia... Op. Cit. pág. 114.

${ }^{27}$ Vid. Prats Catalá, Joan. Las transformaciones de las administraciones públicas de nuestro tiempo. En varios, Estudios para la Reforma de la Administración Pública.Madrid, INAP, 2000. pág. 69.

${ }^{28}$ «Al final, se mantiene la tremenda situación por virtud de la cual un gobierno que tiene la obligación de dar respuestas a la crisis del Estado de bienestar debe, al tiempo, mantener sus prestaciones; una Administración que debe ser eficaz y eficiente debe, a la vez, se profundamente garantista de los derechos reconocidos por el sistema político a los ciudadanos; un funcionario que debe servir a los intereses generales debe, también, servir a sus clientelas particulares». (VILloria Mendieta, Manuel. La modernización ... Op. Cit. pág. 90).

${ }^{29}$ Vid. Hesse, Joachim Jens. »La modernización administrativa y la reforma del sector público en Alemania. Una perspectiva general». Madrid, Revista y Sociedad, 13, 1993. págs. 75-86. 
una rotación baja de gobiernos fomenta la estabilidad y la adaptación institucional gradual. Sin embargo, tal y como observa Joachim Jens Hesee, «En la década entre mediados de los 70 a mediados de los 80 los crecientes déficits presupuestarios conformaron la agenda de la reforma administrativa ${ }^{30}$. En este contexto los programas de reforma se orientan a tres ejes: primero, la imitación del sector privado en la gestión de recursos; segundo, la orientación al ciudadano y la simplificación legal; y como tercer eje, la desburocratización y simplificación administrativa. Todo ello, junto a los factores externos de la europeización, que Alemania trata de liderar, y la unificación, le llevan a iniciativas de modernización en los elementos legales, organizativos y procedimentales ${ }^{31}$.

En su conjunto la desregulación, como eje de la reposición del ámbito privado, afecta a las normas y al sistema jurídico que las produce, el Estado de Derecho, pues sustancialmente supone la retirada con ellas de las potestades públicas que condicionan al ámbito privado. Por otro lado, donde surte un efecto especial y nuevo es en el marco jurídico administrativo, cuya afectación al sistema continental es notablemente más alto, pues las medidas funcionales y organizativas de tipo privatizador en el ámbito público inciden en la concreción práctica del ordenamiento administrativo que evita la utilización del sistema jurídico bajo principios generales y ordenadores, fenómeno que Joan Subirats recoge del siguiente modo:

Empieza a contar más el «resultado» que la legalidad o conformidad a los procedimientos establecidos. Transformándose, paralelamente, la legislación. Pasando de un tipo de normativa de aplicación y contenido generalísticos como guía de la actividad administrativa, a un tipo de reglamentación ad hoc, de alcance limitado y particularizado ${ }^{32}$.

En el caso español la crisis occidental del Estado del bienestar se fragua en plena transición al Estado constitucional definido como social y democrático de Derecho, tal y como proclama el artículo primero de la CE. Hasta entonces las instituciones públicas estaban incardinadas en un régimen autoritario, que fundamentalmente bajo presiones internacionales de tipo económico, se había conformado bajo el imperio del sistema jurídico público concretado en Estado de legalidad. Las deficiencias políticas de dicho régimen tergiversaban el acceso libre al sector privado, más bien favorecido por conceptos

\footnotetext{
${ }^{30}$ Hesse, Joachim Jens. »La modernización...» Op. cit. pág. 77.

${ }^{31}$ Vid. Ibid. pág. 77.

${ }^{32}$ SubIRATS, J. «Notas acerca del Estado, la Administración y las políticas públicas». Revista de Estudios Políticos, nº 59, Enero-marzo, 1988. pág. 178.
} 
oligárquicos de fidelidad al sistema, aunque ya permeable socialmente a nuevos sectores de actividad (en torno a los servicios, el turismo, la construcción y la industria bajo patentes extranjeras, como el automóvil, bienes de equipo y consumo y la pujanza de la economía industrial vasca y catalana) ${ }^{33}$. En torno a este sistema, la protección social se configuraba como una extensión del sistema público de beneficencia inspirado en el esquema liberal clásico y auspiciado por las Diputaciones Provinciales, y se iba ampliando hacia las pujantes clases medias nacidas del desarrollo económico. Sin embargo las características más notables y diferenciales en términos de política económica creaban una escasa presión fiscal y un acentuado uso de la caja del déficit presupuestario en el control de las inversiones públicas $^{34}$.

Con la llegada de la transición política y la crisis económica que antecede al final de la dictadura, el Estado español se enfrenta a los problemas generales de la economía occidental de inflación y estancamiento económico con un sistema prestacional deficiente basado en un profundo desajuste entre los ámbitos público y privado, que descubren una estructura económica altamente desacoplada internamente y con su entorno, principalmente europeo. Ante tales anomalías el Estado del bienestar sigue siendo una tarea pendiente en medio de la necesidad del ajuste del déficit y la nueva presión de organismos económico-financieros estatales e internacionales con las políticas económicas globales que se prescriben como salida general de la crisis. Estas tareas presentan, entre otras, pero dentro del reordenamiento político y administrativo, la solución estratégica de emprender el programa de adhesión a la Comunidad europea, cuyo bloque continental parece que hace posible la superación de la crisis con el mantenimiento -en el caso del Estado español, creación de nueva planta-, del sistema público prestacional y el acceso a los mercados y condiciones económicas de la CEE, al menos hasta su relativa equiparación con el resto de Estados de Europa occidental. Dicha superación implica otras tareas, tales como la reducción del citado déficit, para lo que se encuentra un amplio margen en la implantación de una disciplina fiscal hasta entonces casi inexistente, pero también en la reestructuración económica, fuertemente basada en un empleo de baja productividad y orientado a un mercado interior protegido e

\footnotetext{
${ }^{33}$ Vid. Tamames, Ramón. (dir.). Anuario Económico y social de España. 1977. Barcelona, Planeta, 1977.

${ }^{34}$ Vid. Tamames, Ramón. Estructura económica de España. Madrid, Alianza Editorial, 1978.
} 
intervenido a pesar de su relativa liberalización en la década de los 60. Como herencia de este pasado y su reforma parcial se asentará una propensión estructural a altas cotas de desempleo y precariedad laboral, un control del gasto y del déficit público, y una indisciplina fiscal de amplios sectores económicos en el seno de una economía apalancada en la deuda pública y la baja presión tributaria ${ }^{35}$.

En este ámbito continental, la Comunidad Europea primero, y tras el Tratado de Maastricht, la Unión Europea posteriormente, va dotando a los Estados adheridos y sus respectivas administraciones, de políticas públicas novedosas a través de redes europeas descentralizadas y programas financiados con fondos europeos. Además, el proyecto de unión monetaria, con mandatos de control presupuestario, liberalización comercial y económica. También imponiendo un nuevo marco normativo público a través de Directivas, que constituyen la forma jurídica de trasposición de esas políticas a las legislaciones nacionales.

En el seno de los órganos estables de decisión y gobierno, sustanciados en la Comisión, con las directrices marcadas por el Consejo europeo y los Consejos de ministros, se van aglutinando los grupos de interés y los centros de análisis y gestión de los programas que impulsan dichas políticas. Por otro lado su ejecución va dando un protagonismo creciente al Comité de las Regiones y los territorios europeos infraestatales que van ocupando una posición relevante tanto en los centros decisorios europeos como en los respectivos Estados ${ }^{36}$.

Así, si en el bloque angloamericano la decidida innovación de la gestión pública se desenvuelve a través de instrumentos de renovación privatista, en el bloque continental se produce una asimilación más compleja de estas reformas, que en pocos casos admite desmantelar el Estado social, inherente al modelo de desarrollo social y político construido en un marco jurídico altamente tasado. Sin embargo, en cualquiera de los casos, guiados por los acuerdos y recomendaciones suscritas en diferentes instituciones y convenios de derecho internacional público y privado, ambos bloques se encuentran coordinados en la vuelta al ámbito privado de los medios de gestión

35 Vid. LóPEz GARRIDo, Diego. «El Estado de bienestar: vuelta a la fiscalidad» (artículo publicado en El Pais, 4 de agosto de 2010).

${ }^{36}$ Vid. BAÑón, R. y Manuel Tamayo. «Las relaciones intergubernamentales en España: el nuevo papel de la Administración Central en el modelo de relaciones intergubernamentales». Jornadas sobre el Federalismo, IVAP, Vitoria, 3 y 4 de noviembre. 
administrativos y públicos ${ }^{37}$. Estos acuerdos, globalmente considerados, se materializan en la política fiscal, comercial y reguladora, pues ambos bloques coincidirán en la regla de competencia que se impone desde la gestión pública: contención del gasto público; libertad relativa de intercambios en los mercados, con aceptación por las partes de las medidas proteccionistas agrarias; y desregulación de los servicios públicos de infraestructura y producción hasta entonces restringidos al control público directo e indirecto. Todo ello lleva a un paquete de políticas en cuyo epicentro se encuentra la gestión pública, en la medida que ésta debe soportar medios más eficientes de producción de servicios; técnicas de prestación de servicios que puedan evaluarse en un mercado homologable de creación de valor y calidad de acuerdo a criterios objetivos de obtención de resultados y rendición de cuentas; y por último, retirada de medios jurídicos formales que promueven, al regular los intereses privados, la subjetividad del interés general, pues son éstos los que lo procuran en el nuevo escenario, y en su lugar aparece la autorregulación de los mercados competitivos $^{38}$. Naturalmente que tales formulaciones dogmáticas se someten a múltiples mecanismos correctores que, bajo dichas directrices, precisan proteger estos mercados en función de sus demandas, dando lugar a todas las normativas fragmentadas para tal fin

\footnotetext{
${ }^{37}$ Estas instituciones pueden tener carácter ejecutivo o vinculante en sus disposiciones, como el FMI o los tratados como el GATT; de acuerdos políticos consensuados, como el denominado «consenso de Washington» que da carta de naturaleza a la aplicación política de la denominada doctrina neoliberal en todo el orbe de influencia norteamericana en el hemisferio de América Latina o el Informe de Desarrollo del Banco Mundial para 1996 «del Plan al Mercado» en el de la Federación rusa y los países de Europa del Este; y no preceptivos pero de gran influencia, entre estos se debe destacar papel de la OCDE, cuyos análisis y dictámenes sientan una doctrina de gran peso en las políticas gubernamentales de los países liberal-democráticos desarrollados que, previa admisión, forman parte de esta organización voluntariamente.

${ }^{38}$ Interesa a esta investigación ser estricta en la delimitación entre el ámbito público y privado. Para ciertos autores, como Andrea Lippi, la Administración pública cuando es «entendida como el sistema de administraciones de naturaleza jurídica pública, realizamos una afirmación parcial y empíricamente desviada, dado que [...] 2. La función administrativa con finalidades públicas puede ser realizada independientemente por administraciones de diferente naturaleza jurídica: privadas, públicas y del tercer sector». Se entiende como pauta general de esta investigación que una Administración pública está siempre referida al régimen jurídico público, como hecho positivo y delimitador de su condición objetiva. Cabría en una naturaleza parcialmente privada de una institución pública aplicar la teoría de los actos separables, o en una institución privada su vinculación a un régimen semipúblico (entre otros colegios profesionales o tercer sector cuando esto proceda a través de formas de delegación), de lo contrario quedará excluida la misma titularidad pública y nos situaremos en el ámbito privado. (LIPPI, Andrea y Massimo Morisi. Gestión... Op. Cit. pág. 28).
} 
en función de la correlación de fuerzas que muestran tales demandas $^{39}$.

Sin embargo, tal vez pese a la apariencia contraria, en la renovación de la gestión pública iniciada en la década de los 80 del siglo $\mathrm{XX}$, no se trata, como en los inicios de la revolución liberal, de separar los ámbitos público y privado para dar libertad de acción al último a través de una transformación institucional. Tampoco, como en el ciclo de reformas de la segunda revolución industrial, de subordinar la gestión del ámbito público a las necesidades de dotación de medios al crecimiento del ámbito privado. Por lo tanto, la hipótesis que se formula propone que en esta nueva reposición privada sobre lo público, se trata de: uno, aplicar políticas de gestión, a través de técnicas de organización empresarial, que traspasen los activos de la actividad pública a la gestión privada, capaz de resolver las ineficiencias mostradas por aquella; dos, enajenar la oferta de los poderes de la Administración a la gestión privada en aras a asegurar el crecimiento económico sin constreñirlo a soluciones administrativas, y abrirlo a las técnicas y la gestión indirecta del ámbito privado.

Los automatismos de la «mano invisible» del libre mercado en beneficio del interés general, renuevan la justificación clásica de las capacidades de la voluntad «egoísta» del ámbito privado de dotarse de una dimensión social capaz de suplantar la salvaguarda del interés general, ostentado hasta ahora por los poderes públicos ${ }^{40}$. Voluntad en la que confluyen los intereses particulares con los generales que se conectan con una más eficaz forma de gestión por el desarrollo natural de la eficiencia en la persecución de beneficios y la necesidad de atender las inexorables demandas de una sociedad civil madura en sus niveles de exigencia. Para ello bastan las técnicas de gestión económica, social y de calidad en la prestación de servicios, que per-

${ }^{39}$ Para un desarrollo de concepto: «A. La legitimidad por resultados y la fragmentación»(Cap. IV).Vid. Villoria Mendieta, Manuel. La modernización ... Op. Cit. págs. 105-109.

${ }^{40}$ El neoliberalismo económico no se enfrenta a la misma realidad política de los clásicos: Adam Smith, Stuart Mill, Ricardo,... Los poderes no son ya aquellos privatistas que persiguen un control político para imponer sus intereses sociales estamentales, si no ya liberales, es decir, ejercidos en un marco jurídico que ampara los intereses privados en condiciones de igualdad con prerrogativas que tratan de garantizar la protección de los intereses generales. De algún modo éstos se equiparan a nuevos intereses de tipo burocrático que parasitan en la estructura del Estado liberaldemocrático a modo de nuevos poderes privatistas, situación que permite utilizar formalmente la argumentación clásica. 
miten un marco más flexible de organización y control capaz de prescindir de la excesiva rigidez formal de los controles y las garantías jurídicas ${ }^{41}$.

\section{LA CORRECCIÓN DE LOS MODELOS PRIVATISTAS DE GESTIÓN Y LA BÚSQUEDA DE ENTORNOS DE COOPERACIÓN ENTRE EL ÁMBITO PÚBLICO Y PRIVADO}

Desde una óptica general el modelo privado de gestión se puede definir como un conjunto de técnicas, procesos y procedimientos que tratan de obtener ciertos objetivos de rendimiento en la actividad basados en la creación de un valor entre los recursos empleados en dicha actividad y los resultados obtenidos a través de ella, utilizando para esto generalmente la figura de organizaciones empresariales que establecen sus relaciones internas y externas como sujetos del Derecho privado ${ }^{42}$. Este valor se mide en términos económicos para lo que es imprescindible que los resultados obtenidos en tal actividad puedan materializarse dentro de un mercado capaz de transformalos en moneda o títulos fiduciarios.

En su conexión comparatista con el modelo público, en el modelo privado de gestión aparecen rasgos singulares entre los que destaca la sustitución del interés público como objeto de la actividad, por los intereses y las oportunidades de los mercados, donde se materializan los resultados. En este objetivo privado los procesos de la actividad se definen en la búsqueda permanente de la eficacia cuya evaluación se traduce en indicadores financieros. Esta simplificación formal de los objetivos permite concentrarse en el diseño de los medios técnicos para alcanzarlos, con la menor interferencia en su concepción de premisas y obligaciones externas a los propósitos establecidos, lo que habitualmente se ha identificado con el atributo de la flexibilidad. Naturalmente que el ámbito concreto de las empresas, entidades y grandes corporaciones privadas acentúa sus condicionantes organizativos, bien sea por el entorno competitivo en el que se desenvuel-

${ }^{41}$ Vid. Villoria Mendieta, Manuel. La modernización ... Op. Cit. págs. 266-267

${ }^{42}$ La definición que hace el RAE de la voz privatista es «Persona que profesa el derecho privado, o tiene en él especiales conocimientos». A partir de esta personificación singular se evidencia el contenido jurídico del término, ampliamente, y sobre todo, utilizado en el resto de personificaciones de los sujetos públicos, que en el RAE se aplica a las correspondientes personas privadas, así respecto a las instituciones públicas, las empresas privadas, y respecto al tráfico jurídico administrativo el privado, o en el caso de la actividad pública la actividad mercantil. 
ven, o a medida que aumentan y dependen del impacto social de su actividad, incluso de su poder efectivo sobre la propia sociedad. De alguna manera son fuente inagotable de formas de ejecución de la actividad económica y social que en su abstracción permiten alcanzar altos grados de eficacia en su organización y funcionamiento operativo. Sobre estas premisas se ha visto como el Estado recurre a los medios privados de forma directa e indirecta para la ejecución de las infraestructuras de uso común o la prestación de los servicios bajo tutela pública ${ }^{43}$. También, como se ha observado, al menos desde fines del siglo XIX en la Segunda Revolución Industrial, en los métodos de gestión, organización y funcionamiento interno que asociamos al concepto de gestión pública ${ }^{44}$.

Sin embargo, a mediados de la década de los noventa del siglo XX comienzan a percibirse los primeros síntomas de convulsiones cíclicas en la estabilidad económica fruto de la aplicación de las políticas neoliberales de gestión y regulación económica: afloran los primeros problemas financieros; el fracaso en la exportación de modelos homogéneos de desarrollo; las desigualdades sobre los países en desarrollo y las prácticas proteccionistas frente a ellos por los países industrializados; los problemas medioambientales ante el consumo ilimitado de recursos naturales; el desorden en las redes de tráficos ilegales; la sensación y las evidencias de riesgos generalizados por la pérdida de control y desgobierno ${ }^{45}$. Se percibe que ante un esquema privatista los fines de la actividad social, sea pública o privada, en la búsqueda de resultados, no sólo condicionan la ejecución si no, sobretodo, la consecución de los objetivos. En este sentido las reformas mencionadas en el epígrafe anterior se contradicen con los objetivos de responsabilidad y eficacia que en la acción gubernamental se proponían y, siguiendo el análisis de Joan Prats, lo hacen al menos por dos razones. En primer término el incumplimiento de la hipótesis que postulaba que se puede separar la concepción de la ejecución y por ende la política de su implementación, pues no se trata de dos marcos conceptuales que se pueden interrelacionar, si no de dos etapas de un proceso que se retroalimenta. Esta situación produce vicios de inhibición e irresponsabilidad por la autoridad gubernamental

${ }^{43}$ Vid. Lesmes SerRano, Carlos. „La externalización ....» Op. pág. 16.

${ }^{44}$ A lo largo del epígrafe 3.2: «El paradigma burocrático, su crítica y las razones de su vigencia parcial», Prats se hace eco de un concepto introducido con anterioridad, la vigencia y el carácter privatista de los métodos burocráticos cuando se introducen dentro de la gestión pública. Vid. Prats Catalá, Joan. De la burocracia...Op. Cit. pág. 99-108.

${ }^{45}$ Vid. Prats Catalá, Joan. Las transformaciones... Op. Cit. pág. 27. 
en los defectos de la ejecución. En segundo lugar, la simplificación de los objetivos en programas parciales y su efecto organizativo en la proliferación de entes no gubernamentales y agencias favorece el aislamiento tanto de las acciones públicas como de las entidades que la sustentan, lo que se opone a las exigencias de coordinación y colaboración interadministrativa que imponen las nuevas realidades y necesidades globales y transversales. En este contexto Joan Prats sitúa a la Gobernanza como un marco o paradigma de gestión pública que no elimina el papel de los gobiernos ni las técnicas organizativas asociadas a la burocracia y la gerencia. Se trata más bien de una nueva estructura que se superpone a ambas en la que cobran un papel esencial las redes de actores que intervienen en la gestión y acción del gobierno que pueden ser públicos, privados y no gubernamentales ${ }^{46}$.

En suma, los modelos privatistas de gestión pública se revelan como una solución ante las contradicciones de los modelos públicos de ordenación omnicomprensiva de la vida social, o al menos de grandes parcelas de ella, que acaban traspasando radicalmente las condiciones ambientales en las que puede desenvolverse el ámbito privado. Por lo tanto su revisión no puede volver a los esquemas inmediatamente anteriores puramente gerenciales y continuar una inmersión que anule la necesidad, los fines y la razón de ser del ámbito público. Se tratará de encontrar vías en las que la sociedad civil, paradigma del ámbito privado, coopere con el ámbito público. Que la dirección del citado desarrollo económico y social se efectúe de forma cooperativa entre instancias públicas y privadas alineadas por ese fin común, a través de un marco jurídico más flexible en el que se conjuguen los medios de legalidad pública y privada.

En este sentido si la Nueva Gestión Pública se citaba en M. Barzelay como "campo interdisciplinario orientado a las políticas de acción» y concepto de difícil elaboración, la Gobernanza se plantea como un paradigma corrector, que ante los problemas históricos reseñados de fracaso de un modelo privatista para la gestión del ámbito público en la Administración, buscaría un entorno de cooperación entre el ámbito público y privado. Los medios de dicho entorno se formulan sin renunciar a las "conquistas» del modelo gerencial frente a la organización burocrática, pero considerando los valores inherentes a ésta y su vigencia, y finalmente se presentan como superación de ambos modelos organizativos: «En realidad, sirve para comprender positivamente y reformar normativamente la estructura y procesos de

${ }^{46}$ Vid.Ibid. págs. $70-86$ 
gobernación en todos aquellos ámbitos en que la burocracia o la nueva gerencia pública resultan inapropiadas ${ }^{47}$. Como tal paradigma, busca una formulación teórica que en la práctica no se desentiende del legado del management público y la eclosión en la ciencia administrativa de la crítica a la burocracia, sino que trata de sustanciar en conceptos, ahora más difusos, los hechos producidos en la transformación de la gestión pública. Se instala, en definitiva, en el discurso de la ambigüedad ante la complejidad, pero produciendo un sistema conceptual que en su indeterminación resulta tan abierto como innovador. Una vez más, frente al doble discurso político neoliberal, de denuncia a los excesos del intervencionismo, pero también justificador de la salvación del Estado del Bienestar propio de la nueva gestión pública y su propuesta privatista, la gobernanza se somete asimismo a la doble lectura aceptable para neoliberales y socialdemócratas en la búsqueda, entre otras, de capacidades institucionales con objetivos de calidad en la gestión. En este sentido sus propuestas podrían ser objeto de la siguiente interpretación realizada por J. Kooiman ${ }^{48}$ :

- Desplazamiento del interés general como objeto del ámbito público hacia el ámbito privado, extensivo no sólo al modelo empresarial sino a la sociedad civil que actúa en entidades organizadas de interés público y derecho privado sobre un esquema de cooperación.

- Aceptación de los modelos burocráticos, que se reincorporan, y gerencial, que se mantiene, con la formulación de principios que aplicados flexiblemente forman nuevos modelos de gestión perfilados en conceptos de: competencias de dirección, estrategia, democracia, transparencia y comunicación. Aspectos que junto a la capacidad de adaptación a las situaciones concretas frente a la gestión única y homogénea refuerzan el eclecticismo, la ambigüedad e indeterminación propia de este modelo.

- Énfasis en la interacción, colaboración y participación de múltiples actores para la resolución de los problemas complejos. Adopción de los procedimientos de consenso para afrontar la indeterminación de los objetivos de gobierno cediendo espacios a la discrecionalidad como medio para la eliminación de riesgos en la toma de decisiones.

\footnotetext{
${ }^{47}$ Ibid. págs. 131-133.

${ }^{48}$ Vid. Koolman, J. Governing as Governance, en www.iigov.org. Conferencia Internacional «Democracia, Gobernanza y Bienestar en las Sociedades Globales», Barcelona, 27-29 de noviembre, 2003.
} 
- Institucionalización de la comunicación y los procesos de interacción entre los actores implicados con responsabilidades compartidas con reconocimiento de las individualidades y diferencias. Conduce al rediseño organizativo y funcional para reforzar la cooperación institucional pública y privada en lugar del papel determinante del gobierno.

Sin embargo, este esquema de Gobernanza, más proclive al acomodo del marco jurídico público, no encuentra una solución concreta para sustituir el marco regulador liberal y liberal-democrático vigente en el régimen jurídico administrativo, al tiempo que lo rechaza por las mismas demandas de eficacia y eficiencia surgidas ante las expectativas de cambios radicales en el sector público en su nueva forma de operar. Bajo este paradigma la transformación del Derecho administrativo y de su régimen jurídico regulador se convierte de alguna forma en un problema externo a la propia dinámica del sistema público. Algo que deben resolver los especialistas en Derecho, o de lo contrario, aceptar un nuevo marco técnico donde las funciones de responsabilidad, equidad y control de la discrecionalidad de las decisiones administrativas discurran en definitiva por mecanismos extrajurídicos. Descartada por lo tanto esta opción, surge toda una pléyade de propuestas reformistas en el seno de los teóricos de la Administración: radicalmente críticas con el papel del Derecho administrativo en su concepción clásica; sensu contrario, continuistas y defensores de la ortodoxia dogmática; y por último posiciones absentistas del presunto problema, o eclécticas y voluntaristas en la búsqueda de soluciones multidisciplinarias o intermedias ${ }^{49}$.

En el último bloque de propuestas podemos detenernos en algunas líneas enunciadas por Joan Prats, consecuentes con la búsqueda de los entornos de cooperación entre los modelos de gestión público y privatista, que tratan de establecer los puentes, como exponentes de ambos modelos, entre la nueva cultura gerencial y las vías abiertas para la renovación del Derecho administrativo: pri-

${ }^{49} \mathrm{Vg}$. Joan Prats, cuyo lúcido análisis de esta crisis suscita gran parte de las argumentaciones que se exponen en este y el siguiente epígrafe, llega a proponer como horizonte de solución que «Necesitamos una renovación gerencial de nuestras Administraciones Públicas tanto como una renovación paralela y coherente de su Derecho. Ambos procesos deben tomar como referente la democratización radical de nuestras Administraciones Públicas. Y deben avanzar conjuntamente y en diálogo, pues responden a las exigencias igualmente inexcusables del Estado democrático y social de Derecho y de los principios de eficacia y eficiencia». (Prats CATAlá, Joan. De la burocracia... Op. Cit. pág. 74). 
mero, la contradicción entre el régimen estatutario único de la Administración pública y la heterogeneidad de las organizaciones públicas, que plantea el reto de encontrar mecanismos de integración entre la gestión pública renovada (implícitamente la gobernanza) y el Derecho; segundo, consecuente con la anterior, la particularización de los marcos normativos ante el doble abandono, por un lado de la delimitación técnica entre los medios de planificación y ejecución por la nueva gestión pública, por otro, la particularización de la legislación administrativa; tercero, en la exploración del pluralismo político y administrativo, como expresión de la cláusula democrática del Derecho público, la redefinición del principio de discrecionalidad y responsabilidad consecuente con la diversidad orgánica de la actividad administrativa, mediante la inclusión en la regulación jurídica de mecanismos de participación en los actos administrativos que excluyen al ámbito político; cuarto, el carácter instrumental del Derecho, en el enfoque económico y organizativo de la Ciencia de la Administración, como un elemento más especializado en la aplicación de normas jurídicas superadoras del plano formal y procedimental actual; en quinto y último lugar, matizando la anterior, la aceptación de que la delimitación de los intereses y objetivos públicos no son objeto de la ley, sino de los poderes públicos y la colaboración (persuasión) ciudadana. Estas notas, entre otras, resultan de gran importancia al poner foco en la realidad de la gestión pública, y más que por exponer un estado de opinión, por levantar acta de la heterogeneidad y fragmentación de las normas, la especialización inconexa de los principios del Derecho, y la tendencia extrajurídica a encontrar soluciones institucionalistas y burocráticas a los controles que los enunciados jurídicos y su sistema de funcionamiento y garantías no definen adecuadamente ${ }^{50}$.

En esta situación, más que un modelo definido de Administración, parece que se muestra un sustrato heterogéneo, fragmentado, disperso e indefinido tanto en el campo doctrinal jurídico-público, como en el funcional y político. La forma de reconstrucción del Estado liberal-democrático a que se asiste, parece revelar una comprensión empírica y pragmática en los modos de hacer públicos, cuya inmadurez, a fuer de vigor heurístico enriquecedor, aún no permite vislumbrar un nuevo sistema doctrinal como el que alumbró a fines del XIX la creación del Derecho administrativo.

${ }^{50}$ Vid. Ibid. págs. 127-129. 


\section{LA MARGINALIDAD DEL MARCO JURÍDICO EN LA NUEVA GESTIÓN DE LOS SERVICIOS PÚBLICOS Y SUS FORMAS DE SUPERACIÓN}

En cuanto a la marginalidad del marco jurídico propio, en ocasiones autoimpuesta por éste, respecto a la técnica gestora y productora del servicio público, no impide observar que la adaptación de su régimen de regulación a los medios de prestación determina la organización interna y funciones de aquellos servicios. Como principio general el servicio público, en tanto actividad de la Administración, se define de acuerdo con los objetivos que se persiguen, por lo cual su régimen jurídico, que a su vez contiene principios y objetivos autónomos, constituye desde esta perspectiva un medio más para cumplir aquellos fines $^{51}$. Medio exorbitante del Derecho que permite en su ejecución el uso de las prerrogativas que garantizan la protección de los intereses generales y de los derechos de particulares por los sujetos públicos $^{52}$. Sin embargo esta posición apriorística del Derecho se

${ }^{51}$ Respecto a la teoría del recurso jurídico como uno más de la gestión pública, primo inter pares, citado más arriba en las líneas del movimiento renovador del Derecho: «El Derecho se configura así, en gran parte, como un instrumento o recurso más entre la panoplia de recursos o formas de acción de entre los que deberá optarse de modo diverso y racionalmente fundado en cada caso». (PraTs, Joan. De la burocracia... Op. Cit. pág. 127). En la misma línea argumental encontramos este concepto en tratados académicos de la teoría de la Administración, por ejemplo Lippi y Morisi cuando definen la función administrativa como: «[...] el conjunto de comportamientos de quienes la llevan a cabo y la misma se observa cuando éstos realizan acciones por medio de reglamentos, tecnologías y varios tipos de recursos, atribuyendo un significado a su actividad, la cual, añadimos ahora, para considerarla "administrativa» ha de ser no sólo intencional, sino también finalizada, dirigida a alcanzar un objetivo» (LIPPI, Andrea y Massimo Morisi. Gestión... Op. Cit. pág. 20). En esta investigación es una argumentación que se considera, para matizarse a continuación otorgando a este «recurso jurídico» la cualificación de sus prerrogativas que en la literatura de la gobernanza o la Teoría de Administración no llegan a abordarse en la centralidad que ocupa dentro del Estado de Derecho.

${ }^{52}$ En la doctrina jurídica clásica Garrido Falla consideraba la existencia de una dualidad o «una oposición aparentemente irreductible entre la prerrogativa administrativa y la garantía del particular» (Juan-Cruz Alli. La construcción... Op. Cit. pág. 224) cuya superación dialéctica viene dada por el concepto de servicio público como interés público, lo que daba lugar a la existencia de la figura subordinada a la prerrogativa que se convierte en el elemento distintivo del Derecho especial (administrativo). «Si para la consecución de ciertos fines la Administración no necesita de la prerrogativa, no tiene por qué surgir el Derecho especial». (GARRIDo Falla, »Sobre el Derecho administrativo y sus ideas cardinales». RAP, 7, 1952. pág. 26). Lo que se trata de ver aquí no es el uso del interés público como elemento sustancial del Derecho administrativo, pues «bajo el aspecto jurídico, la tutela de intereses (públicos) se desarrolla de formas tan diversas entre sí, que es difícil encontrar un rasgo unificador común jurídicamente significativo»(GIANNINI, Massimo. Derecho Administrativo. 
compadece de los medios de gestión privatistas que se introducen en la prestación de los servicios públicos. Así, Michael Barzelay, recuperando la vigencia de la doctrina ya enunciada en 1946 por Herbert Simon $^{53}$, pone de manifiesto la precariedad de ese concepto clásico de la Administración en los nuevos postulados de la gestión pública cuando expone: «Simon rechazó pues el postulado general de que las decisiones organizativas debieran adoptarse mediante la aplicación de principios generales a casos concretos». En su lugar las organizaciones públicas deben organizar sus servicios de acuerdo a principios de análisis concretos de la situación que lleven a un diagnóstico del que se deduzca el enfoque de la acción administrativa en el sentido de incrementar sus resultados ${ }^{54}$.

En este sentido el régimen jurídico administrativo, como conjunto de normas de Derecho público aplicadas a la regulación de las actuaciones administrativas, puede parecer llamado a adaptarse de forma concreta al ordenamiento normativo de las actividades y organización de los servicios públicos, por la razón expuesta más arriba, como un medio más ${ }^{55}$. Sin embargo, en su condición de medio específico y rector de regulación de toda la actividad administrativa, también le corresponde definir el marco y los límites de la organización, las funciones y los procedimientos técnicos empleados en el servicio público, modificando con ello en lo que sea preciso los propios objetivos y medios inicialmente previstos en él. A su vez, en su dimensión general, el desarrollo de los fines y principios del régimen jurídico público se pueden ver alterados en sus prerrogativas por la determinación de los servicios públicos en otros órganos constitucionales a través de las normas legislativas que cumplen o desarrollan el bloque de constitucionalidad. Principios tales como los de simplificación, transparencia, confianza y compensación basados en la supremacía del sujeto perceptor del servicio una vez prescrito como de-

Madrid, MAP, 1991.Vol.I. pág. 107) sino, dentro del propio razonamiento jurídico, y por ende en el objeto del Derecho especial, incluir los derechos particulares como formas propias del servicio público que supera así la distinción entre lo administrativo como prerrogativa basada en la interpretación del interés público por la Administración y la confrontación de intereses que escapa al régimen jurídico público.

${ }^{53}$ Vid. Simon, Herbert, A. »The proverbs of Administration». Londres, Public and Administration Review, 6, 1946. págs. 53-67.

${ }^{54}$ Vid. Barcelay, Michael. »La importancia de la Gestión del Cambio en la Administración Pública» en Díaz MÉNDEZ, Antonio y Eloy Cuéllar. (Coord.) Administración Inteligente. Madrid, MAP, 2005. págs. 167-178.

${ }^{5}$ Vid. Nota 51. 
positario del derecho reconocido ${ }^{56}$. Se puede así dar lugar a un doble principio, por una parte de subordinación del servicio público al marco jurídico y, por otra parte, de adaptación del marco jurídico al servicio público que propicie un entendimiento receptivo y eficaz en las sujeciones recíprocas entre el marco técnico y jurídico de la Administración pública ${ }^{57}$.

Caben destacar dos fenómenos relacionados con la quiebra del Estado de Derecho basada en la inadaptación del Derecho administrativo clásico, en lo que Prats denomina: «no sólo la exigencia de los valores de equidad social y participación planteados por la transición al Estado social y democrático de Derecho, sino también nuevas exigencias de eficacia y eficiencia en el uso de los recursos públicos» ${ }^{58}$. En la primera se expresan las dificultades de adaptación de la legalidad liberal fundada en el Derecho administrativo a los objetivos del Estado del bienestar; en la segunda se asumen estas carencias del Derecho como limitaciones del citado Estado del bienestar o social y síntomas, antes que causas, de su inviabilidad, que conducen a la crisis de crecimiento, o en términos políticos, de desarrollo económico y social. Al relacionarse ambas, el ámbito privado que se opone al ámbito público que ostenta el Estado social promueve la anulación de

${ }^{56}$ Es en este contexto donde aparece la nueva Ley 4/1999 de 13 de enero de modificación de la Ley 30/1992 de 26 de noviembre, de Régimen Jurídico de las Administraciones Públicas y del Procedimiento Administrativo Común, que en su exposición de motivos pone de manifiesto que «los modelos administrativos deben construirse siempre en función de los ciudadanos, y no al revés. Por ello, también en el proceso de reforma de la Ley 30/1992 se ha tenido como objetivo esta orientación general que debe presidir todas y cada una de las manifestaciones de la reforma administrativa, puesto que la Constitución de 1978 ha querido señalar solemnemente en su artículo 103 que la Administración Pública sirve con objetividad los intereses generales». Más allá del fondo de principios que trata de sustanciar esta Ley reformadora se percibe en ella un contenido garantizador que entra en una casuística muy específica como la que afecta al título VII que no evita una especial complejidad en su aplicación efectiva.

${ }^{57}$ En torno al concepto de dirección de los procesos sociales y la influencia del Derecho en el despliegue de la eficacia de esta dirección aparece la figura de Schmidt-Assmann: «De acuerdo con la teoría de la dirección, el Derecho no constituye el único medio de dirección de los procesos sociales, puesto que también lo son el mercado, el personal y la organización [...] Sus efectos han de ponerse en relación con los demás medios; se han de hallar sus respectivos equivalentes funcionales y contrastar los efectos que producen cada uno de esos medios, a fin de mejorar eventualmente su eficacia». (SchmidT-AssmanN, Eberhard. „Cuestiones fundamentales sobre la reforma de la teoría general del Derecho Administrativo. Necesidad de la innovación y presupuestos metodológicos» en BARNES VÁzQUEZ, Javier (Ed.). Innovación... Op. Cit. pág. 40).

${ }^{58}$ Prats Catalá, Joan. De la burocracia... Op. Cit. pág. 70. 
los sistemas jurídicos de control por viejos e ineficaces ${ }^{59}$. Como señala el propio Prats, esta visión conducía a errores rápidamente detectados: «El desconocimiento u olvido de las constricciones específicas de la gestión pública llevó a bastantes políticos y gerentes poco escrupulosos a ver en el management el saber legitimador no de un nuevo y más eficiente sistema de responsabilidad, sino de una mayor libertad de acción, la cual, desbridada, no ha podido sino incrementar la arbitraiedad del poder $y$, con ella, el potencial de corrupción ${ }^{60}$.

La codificación de los Derechos administrativos delimitó el modelo de Estado con un desarrollo jurídico que trazó paralelamente la protección de los intereses privados con la interdicción de la arbitrariedad y el afianzamiento de las prerrogativas de los poderes públicos para la defensa del interés general. Ahora ya no es el Estado, sino el propio Gobierno y la Administración las que se están redefiniendo, y el Estado de Derecho reclama un nuevo posicionamiento adaptado a esa evolución y la atenta interpretación de su extensa base positiva actual. Este es el funcionamiento del Estado liberal, y por ende, del Estado democrático, y ante él sólo aparecen tareas de indudable quehacer jurídico para acometer la renovación del marco jurídico público.

Este quehacer jurídico Luciano Parejo lo sitúa en el Derecho administrativo general, en su relación con el Derecho Administrativo jurídico-positivo que ha quedado, en esta opinión, profundamente desalineado, particularmente en el caso español ${ }^{61}$. Dicha desactualización supone una clave del desarrollo doctrinal pendiente de resolver que provoca, entre otros, el problema de la «huida del Derecho» y cierta complaciente formulación a veces retórica del mismo ${ }^{62}$. No se trata del abandono del marco jurídico, que sigue existiendo, en el que se deben desenvolver y fijar los límites y en ocasiones las mismas especificaciones o definiciones de los actos y funciones públicas, sino

${ }^{59} \mathrm{Al}$ respecto Joan Prats menciona lo siguiente: «Lo que sucedió es que la eficacia y la eficiencia se atribuyeron al sector privado y fueron a buscarse en los saberes y técnicas de gestión que le son propios, es decir, en el management. Escuelas de negocios y consultoras privadas pasaron a ser los formadores orgánicos de las Administraciones de este tiempo.» (Ibid. pág. 70)

${ }^{60}$ Ibid. pág. 70.

${ }^{61}$ Vid. PAREJo, Luciano. «La idea de la reforma del Derecho Administrativo General. Su planteamiento en España» en BARNES VÁzouEz, Javier (Ed.). Innovación... Op. Cit. pág. 181.

${ }^{62}$ Desarrollando este concepto, véase la interesante recopilación de trabajos recogida en VARIOS. Administración instrumental. Libro homenaje a Manuel Francisco Clavero Arévalo. 2 vols. Instituto García Oviedo, Madrid, 1994 
de la pérdida de su fijación en un ámbito público jurídicamente delimitado, como corresponde a la concepción del Estado de Derecho continental. Así, la preocupante cuestión que suscita la fragmentación y dispersión legislativa y normativa, es fuente por su complejidad de inseguridad jurídica, ejercicio de la arbitrariedad y falta de control de la discrecionalidad, que tiende a producirse amparada en la dispersión de las normas y la pluralidad de exégesis que ésta permite sólo a veces en la calificación competencial de la norma a aplicar ${ }^{63}$.

Respecto a los posicionamientos de la doctrina, levantar acta de esta situación ampliamente contrastada por la crítica, ha dado lugar al menos a tres grandes posiciones razonablemente actuales ante el análisis de las tendencias privatistas del marco jurídico-administrativo: una primera que se puede considerar indiferente, pues entiende que tales tendencias no conculcan los intereses esenciales de mantenimiento del negocio jurídico abierto a una mayor capacidad de elección de sus medios de actuación; la segunda se asienta en la defensa de los valores tradicionales del Derecho administrativo clásico, enroque que permite por una parte acudir a certidumbres dogmáticas que sin duda no perderán su vigencia, y por otra abstenerse de amparar ningún esquema privatista, dejándolo dudosamente sujeto al marco regulador público resultante; como tercera y última posición, la que propugna un firme cambio de pensamiento del Derecho administrativo en su adaptación a las transformaciones socioeconómicas y del desarrollo científico y técnico acaecidos en las últimas décadas en la Administración, sin embargo debe considerarse completamente afín a la ciencia jurídica, pues promueve la renovación de fondo de los contenidos con el propósito de mantener la misma misión formal de la doctrina incluyendo su fundamentación dogmática, orientadora y directora de la organización, funciones y actividad de la Administración.

Paradójicamente, como se anticipaba en el epígrafe II, el neoliberalismo en tanto praxis de su doctrina política, se contradice sustan-

${ }^{63}$ Sobre los procesos de fragmentación en la nueva legitimación que introduce el Estado del bienestar y desarrolla el modelo gerencial, véase VILLORIA, Manuel, La modernización... Op. Cit. págs. 105-109 (Cap. IV. A. «La legitimidad por resultados y la fragmentación»). Es interesante seguir este hilo de la legitimación institucional, que podríamos llamar práctica en su distinción de la formal que se consideraría a la jurídica, Olías de Lima la desarrolla en relación a la prestación de los servicios públicos en el epígrafe 2. «La construcción de legitimidad» de su trabajo: Vid. OLÍAS DE LIMA, Blanca. "Rendimiento institucional, ética y democracia» en DíAz MÉNDEZ, Antonio y Eloy Cuéllar. (Coord.) Administración Inteligente. Madrid, MAP, 2005. págs. 179-196. 
cialmente con los principios del liberalismo originario, en la medida que prescinde de los instrumentos jurídicos que fundamentan su existencia en la delimitación entre el ámbito público y privado, ideados en realidad para proteger a este último de la apropiación patrimonial del primero, que históricamente había coartado el ejercicio de las libertades económicas y políticas. Indiferencia y postulación dogmática parecen las principales salidas al análisis del marco jurídico administrativo ante estas «amenazas» desde las que, sin embargo, afloran importantes aportaciones en la «tercera vía», como las del profesor Parejo, que como él mismo reconoce, no dejan de ser una «muy meritoria tarea cumplida aisladamente por algunos autores ya en la década de los noventa y hasta hoy», dejando caer de soslayo que hasta ahora resultan más voluntaristas que fructíferas ${ }^{64}$ :

La reacción en el sentido simplemente de encajar en el edificio establecido el nuevo orden constitucional (sin consideración efectiva, además, de la importancia real del orden comunitario europeo), conducente a una comprensión demasiado rígida de la relación entre Derecho Constitucional y Administrativo, ha acabado cegando las posibilidades de generación de las condiciones para la puesta en marcha de un verdadero proceso de reforma del Derecho Administrativo como tal. La prueba está en la en la visible pérdida por la ciencia jurídico-administrativa de su papel orientador. El resultado está siendo la huida hacia el estudio de cuestiones concretas, con abandono de toda verdadera preocupación por la construcción sistemática de conjunto ${ }^{65}$.

Expresando el diagnóstico de Luciano Parejo como grandes líneas de acción en la tarea de renovación del marco jurídico público, se señalan: 1. la realimentación de la doctrina del TC y el propio desarrollo legislativo para la revisión de la actual dogmática; 2 . la ade-

\footnotetext{
${ }^{64}$ Además de la aportación citada a continuación y las contribuciones en esta línea insertas en las diferentes temáticas abordadas por este autor, que se irán considerando a lo largo de esta investigación, expresamente relacionadas con la reforma administrativa, caben destacar: PAREJO ALFONSO, Luciano. Crisis y renovación en el Derecho público. Madrid, CES, 1991. También «El ciudadano y el administrado ante la Administración y su actuación, especialmente la cumplida a través del procedimiento». En VV. AA.. Administraciones Públicas y Constitución. Reflexiones sobre el XX Aniversario de la Constitución Española de 1978. Madrid, MAP, 1998. Por último, aunque primera cronológicamente, que el mismo autor incluye entre «los tímidos intentos habidos en la década de los ochenta por suscitar en la doctrina científica un proceso de reforma desde la óptica de la constitucionalización del Derecho Administrativo» (PARejo Alfonso, L. Estado social y Administración Pública. Madrid, Civitas, 1983).

${ }^{65}$ PAREJo, Luciano. «La idea...» Op. Cit. pág. 182
} 
cuación entre las categorías tradicionales de la Parte General y la rápida evolución de la Parte Especial alimentada por el Derecho Comunitario europeo, la acomodación legislativa a las exigencias socioeconómicas y la diversificación competencial territorial; 3. La actualización con los estudios monográficos de los nuevos sectores administrativos suscitados en la gobernación europea; 4. la anticipación a los procesos de aplicación de los bloques de constitucionalidad europeo y territorial del Estado español. En resumen, la transformación y reforma del Derecho administrativo impone bajo esta perspectiva una canalización de la especialización administrativa que sea capaz de orientar las cuestiones centrales a través de un renovado sistema de "categorías, institutos y técnicas» ${ }^{66}$.

En la propuesta de reforma del Derecho administrativo, como forma continental del marco jurídico propio de la Administración, en sus concomitancias con la modernización y reforma administrativa, es destacable la vanguardia de la doctrina alemana, que cumple los tres pilares básicos que se vislumbran para dicha reforma en la perspectiva del caso español arriba expuesta: experiencia en el desarrollo constitucional, recepción del Derecho comunitario y asentamiento y evolución de la doctrina. En este desarrollo resultan muy notables las aportaciones de Schmidt-Assmann ${ }^{67}$. Entre sus principales notas sobre la reforma de la doctrina general, cuyo correlato de contradicciones y analogías con el resto de medios técnicos de la Administración debe ser objeto de estudio específico, figuran concisamente enunciadas, las siguientes:

La focalización en la doctrina general como parte reformable del Derecho administrativo, para lo cual su reformulación debe tomar como referente los apartados de: uno, la jurisprudencia, especialmente la que amplía el bloque de constitucionalidad; dos, la legisladora, en la medida que se transforma en ella el propio contenido del Derecho; tres, la acción del gobierno como eje director en la elaboración de proyectos de ley y normas reglamentarias de efectos transformadores en materias específicas y de nueva regulación. Todas ellas se complementan entre sí para procurar los medios de esta re-

${ }^{66}$ Ibid. págs. 183-185

${ }^{67}$ Vid. Schmidt-Assmann, Eberhard. "Cuestiones...» Op. Cit. págs. 15-132. En esta formulación se sigue el marco conceptual propuesto por este autor.También en la misma edición «Método de la ciencia administrativa» Op. Cit. págs. 133-178. En esta formulación se sigue el marco conceptual propuesto por este autor. Por último dentro de su obra general: SchmidT-Assmann, Eberhard. Teoría general del Derecho administrativo como sistema. Madrid, Marcial Pons-INAP, 2003. 
forma, que en Alemania se ha debatido formulándose como mejora de las condiciones de eficacia del Derecho Administrativo.

La insuficiencia de la concepción tradicional del Derecho administrativo para Schmidt-Assmann se basa en la prevalencia última de la ley, que predetermina la conducta de la Administración por encima del procedimiento. Esta última idea, se matiza aquí, podría hasta cuestionarse, pues en el más típico estilo procesal también las normas de procedimiento son objeto de legislación específica que les otorga la misma relevancia que a la legalidad material de las resoluciones administrativas. Estilo procesal que en definitiva concuerda con la premisa de la correspondencia entre la decisión administrativa con la judicial. Sin embargo este modelo se desvía de la práctica, no actualmente, sino desde los tiempos del Derecho administrativo tradicional, que ya mostraba, como ahora, una actuación informal ante los estándares, procedimientos o relaciones formalizadas (por ejemplo ante el Derecho administrativo económico).

La definición positiva de la Administración, frente a la residual que sólo abarca lo no afectado por los otros dos poderes, que sitúa a la distinción entre Estado y sociedad como lo esencial de su realidad. Esta delimitación da lugar a entender un modelo más real y abierto: con un núcleo interno que regula sus potestades y requisitos de legitimidad y capas externas donde se producen los mayores avances en la clasificación de las relaciones jurídicas. Es en estas capas, donde se producen sus relaciones con la esfera social y aparecen los actos jurídicos necesitados de legitimación, en las que «habrá de transponerse ese objetivo [del Derecho administrativo] a nivel dogmático» ${ }^{68}$.

A modo de conclusión con las premisas anteriores, como una aproximación heurística en la que ahora no se pretende profundizar, el propio Schmidt-Assmann propone ciertas grandes líneas para la reforma del Derecho administrativo:

En torno a la ciencia de la dirección el Derecho se ve comprometido no sólo con la dogmática de las instituciones y reglas, sino en torno al principio de eficacia, como ciencia de dirección, «ciencia que aspira a dirigir con eficacia los procesos sociales ${ }^{69}$. Se orienta para ello a incluir las estructuras reguladoras entendidas como los programas legales de aplicación directa y los instrumentos financieros, de organización y procedimiento. En este sentido, aun aceptando la falta de un perfil conceptual definido de la gobernanza en la ciencia

\footnotetext{
${ }^{68}$ Ibid. pág. 34

${ }^{69}$ Ibid. pág. 38.
} 
jurídica, se permite poner el acento en la regulación de la multiplicidad de actores públicos y privados e instancias nacionales y supranacionales que intervienen en la dirección del ámbito público ${ }^{70}$.

El desarrollo y aplicación del Derecho administrativo como «Derecho Constitucional concretizado», entendido no como un mero desarrollo del segundo en el primero sino considerando la «relación circular» y complementaria entre ambos y las directrices de las cláusulas del Estado de Derecho, el Principio democrático, la «estatalidad abierta» en cuanto a las relaciones con el Derecho Internacional y el Derecho Comunitario ${ }^{71}$ y el principio o la cláusula del Estado social.

Más difusa en su definición, pero como un planteamiento clave de la reforma, se propone la explotación de los recursos generados en la parte especial del Derecho administrativo, extrayendo mediante su generalización los principios de nueva aplicación en los sectores más dinámicos. Se sugiere añadir de forma particular, a los ya tradicionales de seguridad ciudadana, régimen local, urbanismo y función pública, aquellos en los que se ponen de manifiesto las nuevas áreas de responsabilidad pública que se van gestando en la realidad social y económica: como el Derecho económico, las prestaciones sociales y la gestión del medio ambiente.

Más allá del desarrollo de este sustrato reformista, sólidamente anclado en la propia dogmática jurídica y la evolución de la gestión de los servicios públicos y los métodos de gobierno afines al conglomerado de la modernización administrativa, cabe señalar el amplio horizonte de superación que se vislumbra en el marco jurídico administrativo, y de su mano, del papel del ámbito público en el Estado liberal-democrático, social y de Derecho, como sujeto incuestionable del mismo. Todo ello en la medida en que, bajo otras formas de organización y funcionamiento, el ámbito público parece que en realidad se sigue extendiendo en la dirección de la sociedad, si bien puede que con un déficit en las directrices de regulación jurídica que puede desembocar en la pérdida de la protección del interés general y los derechos fundamentales, ahora ya no sólo como aquella expresión formal del Estado censitario, incluso del cercano autoritario, sino por el actual mandato constitucional, en la protección material de contenido social y democrático.

\footnotetext{
${ }^{70}$ Sobre el tema de la dirección como función del Derecho, Vid. SchmidT-AssmanN, Eberhard. Teoría General... Op. Cit. págs. 27 y s.

${ }^{71}$ Quedaría recogido en los artículos 23 y 24 de la Constitución alemana o de forma análoga a este último por el artículo 93 de la CE.
} 
